\title{
Identification of a single nucleotide insertion polymorphism in the upstream region of the insulin promoter factor-1 gene: an association study with diabetes mellitus
}

\author{
K. Yamada, X. Yuan, S. Ishiyama, F. Ichikawa, S. Kohno, S. Shoji, H. Hayashi, K. Nonaka \\ Division of Endocrinology and Metabolism, Department of Medicine, Kurume University School of Medicine, Kurume, Japan
}

\begin{abstract}
Summary Insulin promoter factor 1 (IPF1) is a key factor both for the regulation of insulin gene expression and for the development of the pancreas. In this study 88 patients with non-insulin-dependent diabetes mellitus (NIDDM) who were diagnosed as diabetic at less than 40 years of age, 55 patients with insulindependent-diabetes (IDDM), and 67 normal control subjects were analysed for variants in the upstream region of the IPF1 gene by direct sequencing. A novel single nucleotide insertion polymorphism was found in a guanine triplet at $108 \mathrm{bp}$ upstream of the translation start site. The $\mathrm{G}$ insertion allele (G4 allele) was found to be common in the Japanese population, at a frequency of 0.50 . The prevalence of G3 homozygotes was higher in IDDM patients $(35 \%)$ and lower in NIDDM patients $(17 \%)$ than in normal control
\end{abstract}

subjects $(28 \%, p=0.049)$. In the NIDDM group, the ratio of insulin treatment tended to be higher in subjects homozygous for the G3 allele, although the genotype was not significantly associated with basal Cpeptide levels. The polymorphism is unlikely to be a major contributor to the insulin deficiency of diabetes. However, the polymorphic locus, or an unknown mutation which is in linkage disequilibrium with the polymorphism, could be involved in the pathophysiology of diabetes. The high heterozygosity may be useful for genetic linkage studies of other mutations within and near the IPF1 gene. [Diabetologia (1998) 41: 603-605]

Keywords Insulin promoter factor 1, polymorphism, mutation, insulin-dependency.
Insulin promoter factor 1 (IPF1, also known as STF1, IDX1 and PDX1) is a homeodomain-containing protein which is a key factor in the regulation of the insulin gene in pancreatic beta cells [1,2], and is critical for the development of the pancreas [3, 4]. Although most pancreatic cells express IPF1 during development, its expression becomes limited to beta cells on their maturation. IPF-1-deficient mice, created by gene target-

Received: 15 October 1997 and in revised form: 21 January 1998

Corresponding author: Dr. K. Yamada, Division of Endocrinology and Metabolism, Department of Medicine, Kurume University School of Medicine, 67 Asahimachi, Kurume 830, Japan

Abbreviations: IPF1, Insulin promoter factor 1; NIDDM, noninsulin-dependent diabetes mellitus; IDDM, insulin-dependent diabetes mellitus; PCR, polymerase chain reaction. ing, selectively lack the pancreas at birth, indicating that IPF1 is needed for pancreas formation [3].

A patient with pancreatic agenesis and insulin-deficient diabetes was found to have a single nucleotide deletion in codon 63 of the IPF1 gene causing a frame shift at the transactivation domain [4]. In the heterozygous state this mutation may result in non-insulin-dependent diabetes mellitus (NIDDM), because both parents, each of whom was heterozygous for the same nucleotide deletion, had NIDDM [4]. Thus, an abnormality of the structure or expression of this gene is a possible candidate for the inherited component of diabetes. It is, however, unlikely that major defects in the coding region are involved in common forms of diabetes, because pancreatic agenesis is an extremely rare congenital anomaly. To test the hypothesis that genetic variants in the IPF1 gene upstream region influence the expression of the IPF1 gene, and thereby contribute to the inherited 


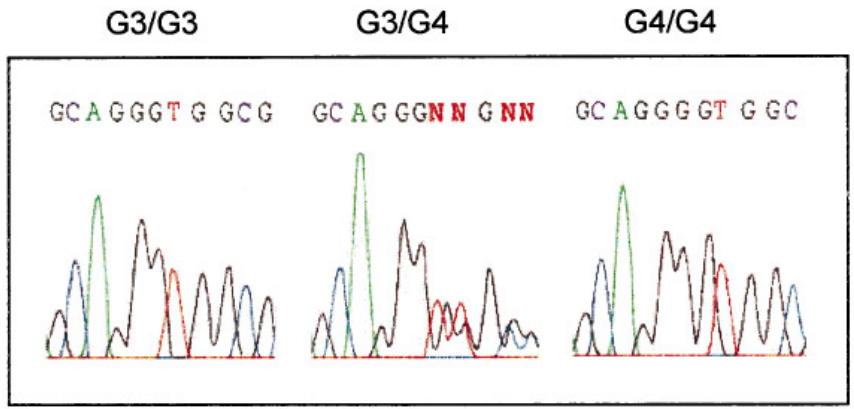

Fig.1. Sequence electropherograms representing the single nucleotide insertion polymorphism at a guanine triplet at -108 from the translation start site

predisposition to diabetes, we analysed the IPF1 gene using polymerase chain reaction (PCR) and a direct sequencing method.

\section{Subjects and methods}

We studied a group of 210 Japanese subjects comprising 88 patients with NIDDM, 55 patients with insulin-dependent diabetes mellitus (IDDM) and 67 control subjects. All patients with NIDDM ( 66 men and 22 women), had been diagnosed as having diabetes at less than 40 years of age. IDDM patients aged $26.8 \pm 14.6$ years (mean \pm SD) consisted of 21 men and 34 women. Control subjects were found to have normal glucose tolerance in a $75 \mathrm{~g}$ oral glucose tolerance test according to World Health Organization criteria. We recruited normal subjects aged 50 years or more to exclude prediabetic subjects.

Amplification of the IPF1 upstream sequence and a part of exon 1 was performed by PCR in a $10 \mu \mathrm{l}$ volume containing $1.5 \mathrm{mmol} / 1 \mathrm{MgCl}_{2}, 0.25 \mathrm{U}$ of AmpliTaq Gold DNA polymerase (Perkin Elmer, Branchburg, N. J., USA), and 5 pmol of the following oligonucleotide primers: 5'-TACCTGGGCCTAGCCTCTTA-3' and 5'-CCCATGTACAGGCACGCAGG-3'. After 9-min pre-heating at $96^{\circ} \mathrm{C}$, amplification was carried out for 35 cycles; each cycle consisting of denaturation at $94^{\circ} \mathrm{C}$ for $1 \mathrm{~min}$, annealing at $63^{\circ} \mathrm{C}$ for $1 \mathrm{~min}$, and extension at $72^{\circ} \mathrm{C}$ for $1 \mathrm{~min}$. Cycle sequencing of PCR products was performed using both sense and antisense primers in different reactions with AmpliTaq DNA polymerase and dichlororhodamine dye terminaters (Applied Biosystems, Foster City, Calif., USA). After removal of excess dye terminators with Centri-Sep spin columns (Princeton Separations, Adelphia, N.J., USA), samples were electrophoresed and analysed on an ABI Prism 310 automated sequencer (PE Applied Biosystems).

Statistical analysis. The results are presented as means \pm SD. Differences between group means were estimated by the Kruskal-Wallis test. The chi-square test was used to compare frequencies. A $p$ value less than 0.05 was considered statistically significant.

\section{Results}

We analysed $343 \mathrm{bp}$ of the IPF1 gene including 247 bp of the $5^{\prime}$ untranslated region and $96 \mathrm{bp}$ of exon 1 by PCR and direct sequencing. A novel single nu-
Table 1. Genotypes and allele frequencies of G3/G4 polymorphism of the IPF1 gene upstream region

\begin{tabular}{lrllll}
\hline & Number & \multicolumn{2}{l}{ Genotype } & \multirow{2}{*}{$\begin{array}{l}\text { G4 allele } \\
\text { frequency }\end{array}$} \\
\cline { 3 - 5 } & & G3/G3 & G3/G4 & G4/G4 & \\
\hline Normal & 67 & $19(28 \%)$ & $28(42 \%)$ & $20(30 \%)$ & 0.51 \\
NIDDM & 88 & $15(17)$ & $52(59)$ & $21(24)$ & 0.53 \\
IDDM & 55 & $19(35)$ & $24(43)$ & $12(22)$ & 0.44 \\
Total & 210 & $53(25)$ & $104(50)$ & $53(25)$ & 0.50 \\
\hline
\end{tabular}

$p=0.049 \mathrm{G} 3 / \mathrm{G} 3$ vs $\mathrm{G} 4 / \mathrm{X}$ by chi-square test

cleotide insertion polymorphism was identified in a guanine triplet at $108 \mathrm{bp}$ upstream of the translation start site. The insertion of a guanine nucleotide $(\mathrm{GGG} \rightarrow \mathrm{GGGG})$ in heterozygous and homozygous states is shown in Fig. 1. The G insertion allele (G4 allele) was common in the Japanese population, at a frequency of 0.50 (Table 1). The G4 allele frequency was slightly higher in patients with NIDDM (0.53), and slightly lower in IDDM (0.44), although it did not reach statistical significance. When comparing the distribution of genotypes among NIDDM, IDDM and normal subjects, the prevalence of G3 homozygotes was higher in IDDM patients $(35 \%)$ and lower in NIDDM patients $(17 \%)$ than normal control subjects $(28 \%)(p=0.049, \mathrm{G} 3 / \mathrm{G} 3$ vs G4/X).

In the NIDDM group, 8 of 15 patients homozygous for the G3 allele (53\%), 24 of 52 heterozygous patients $(46 \%)$, and 7 of 21 individuals homozygous for the $\mathrm{G} 4$ allele (33\%) were receiving insulin therapy (NS). Basal C-peptide levels in G3 homozygotes, heterozygotes, and G4 homozygotes were $1.5 \pm 1.1$, $2.1 \pm 1.4$, and $2.0 \pm 1.8 \mathrm{ng} / \mathrm{ml}$, respectively (NS). No significant association was observed between the genotypes of the IPF1 gene and the age of diagnosis, body mass index, serum lipid levels, or blood pressure, either in NIDDM patients or in IDDM patients. No other nucleotide alterations were found in the region studied in this study.

\section{Discussion}

IPF1 is a key factor both for the regulation of insulin gene expression and for the development of the pancreas. IPF1-containing stem cells are essential for beta-cell regeneration after injury in pancreatic islets [5]. Decrease of the IPF1 content in beta cells exposed to supraphysiological levels of glucose is considered to be a mechanism for glucose toxic effects on the beta cells leading to defective insulin secretion and worsening of hyperglycaemia [6]. Thus, IPF1 is a plausible candidate gene for NIDDM and non-autoimmune IDDM. Inoue et al. [2] analysed the homeodomain region in exon 2 by PCR and single-strand conformation polymorphism, and found no aberrant 
pattern in 61 Japanese patients with late-onset NIDDM.

In this study we identified a single nucleotide insertion polymorphic site in the upstream untranslated region. Neither the NIDDM patients nor the IDDM patients showed a significant difference in the allele frequency when compared with normal control subjects. Hence the polymorphism is unlikely to make a major contribution to the insulin deficiency of diabetes. However, a borderline significant difference was found in the prevalence of G3 homozygotes among patients with NIDDM, patients with IDDM, and non-diabetic subjects; the frequency of the G3/G3 genotype was higher in IDDM than in NIDDM patients. In the NIDDM group, the ratio of insulin treatment tended to be higher in subjects homozygous for the G3 allele. These observations suggest that the polymorphic locus, or an unknown nearby mutation with which the polymorphism is in linkage disequilibrium, may influence the expression of the IPF1 gene, and thus play a role in the pathophysiology of diabetes.

Although further investigations are required to determine the functional significance of the polymorphism in diabetes, the high heterozygosity $(50 \%)$ may be useful for genetic linkage studies of other mutations within and near the IPF1 gene.

\section{References}

1. Ohlsson H, Karlsson K, Edlund T (1993) IPF1, a homeodomain-containing transactivator of the insulin gene. EMBO J 12: 4251-4259

2. Inoue H, Riggs AC, Tanizawa Y et al. (1996) Isolation, characterization, and chromosomal mapping of the human insulin promoter factor 1 (IPF-1) gene. Diabetes 45: 789-794

3. Jonsson J, Carlsson L, Edlund T, Edlund H (1994) Insulinpromoter-factor 1 is required for pancreas development in mice. Nature 371: 606-609

4. Stoffers DA, Zinkin NT, Stanojevic V, Clarke WL, Habener JF (1997) Pancreatic agenesis attributable to a single nucleotide deletion in the human IPF1 gene coding sequence. Nature Genetics 15: 106-110

5. Fernandes A, King LC, Guz Y, Stein R, Wright CVE, Teitelman G (1997) Differentiation of new insulin-producing cells is induced by injury in adult pancreatic islets. Endocrinology 138: $1750-1762$

6. Olson LK, Sharma A, Peshavaria M et al. (1995) Reduction of insulin gene transcription in HIT-T15 beta cells chronically exposed to a supraphysiological glucose concentration is associated with loss of STF-1 transcription factor expression. Proc Natl Acad Sci USA 92: 9127-9131 